\section{Commentary: A step towards better understanding severe mitral regurgitation}

\author{
D. Alan Herbst, MD, and Pavan Atluri, MD
}

Mitral regurgitation (MR) is the most common valvular disorder in the United States. ${ }^{1}$ In asymptomatic patients with primary MR and initial preservation of ejection fraction, survival at 5 years is as low as $65 \%$ and high likelihood exists that surgical intervention will be needed within 6 to 10 years of diagnosis. ${ }^{2,3}$ Current guidelines from the American Heart Association recommend mitral valve surgery for asymptomatic patients with a left ventricular ejection fraction (LVEF) $<60 \%$ or ventricular end systolic diameter $>40 \mathrm{~mm} .{ }^{4}$ However, these parameters may be capturing later stages of ventricular dysfunction, as the natural course of severe MR is not well-understood.

In this issue of the Journal, Corporan and colleagues ${ }^{5}$ report one of the first studies to examine the longitudinal remodeling of the left ventricle that occurs as a result of hemodynamic stress from primary MR. A novel and unique model of severe MR in rats was induced by puncturing the anterior mitral valve leaflet with a $23-G$ needle under ultrasound guidance. Biweekly cardiac echocardiography for up to 40 weeks was performed to measure changes in left ventricular structure and function. Pronounced dilation of the left ventricle occurred well before drop in LVEF, with significant increase in left ventricular end-diastolic volume from baseline by $28 \%$ in 2 weeks and $65 \%$ at 10 weeks. A significant drop in LVEF was not measured until 14 weeks, which is a considerable delay and corresponds to 5 human years.

Corporan and colleagues provide an important foundational block to understanding the long-term effects of severe MR. Their data suggest increased left

\footnotetext{
From the Division of Cardiovascular Surgery, Department of surgery, The Hospital of the University of Pennsylvania, Philadelphia, Pa.

Disclosures: The authors reported no conflicts of interest.

The Journal policy requires editors and reviewers to disclose conflicts of interest and to decline handling or reviewing manuscripts for which they may have a conflict of interest. The editors and reviewers of this article have no conflicts of interest.

Received for publication Sept 8, 2020; revisions received Sept 8, 2020; accepted for publication Sept 9, 2020; available ahead of print Sept 12, 2020.

Address for reprints: Pavan Atluri, MD, The Hospital of the University of Pennsylvania, 3400 Spruce St, Philadelphia, PA 19104 (E-mail: Pavan.Atluri@ pennmedicine.upenn.edu).

J Thorac Cardiovasc Surg 2021;161:977-8

$0022-5223 / \$ 36.00$

Copyright (c) 2020 by The American Association for Thoracic Surgery

https://doi.org/10.1016/j.jtcvs.2020.09.033
}

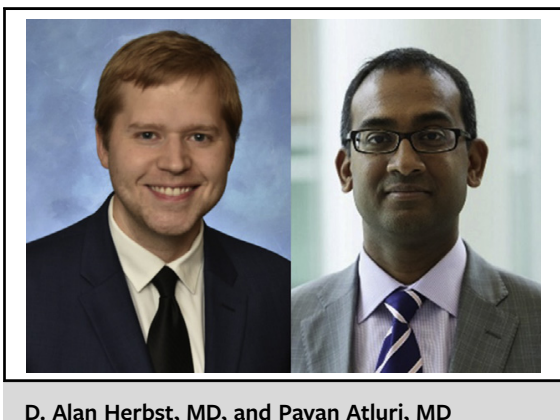

D. Alan Herbst, MD, and Pavan Atluri, MD

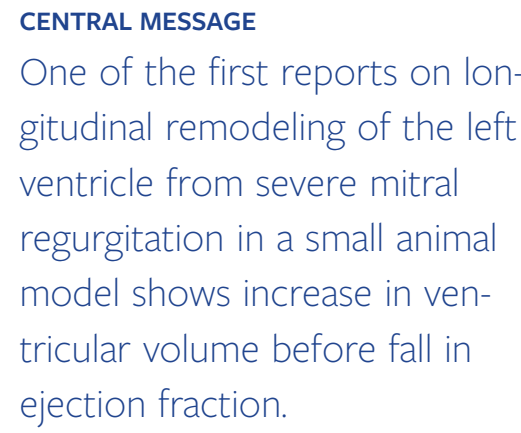

ventricular volume is a herald for ventricular dysfunction and precedes a fall in ejection fraction. The model of injury employed, while novel, may be a closer measure of acute MR and demonstrates the physiologic stress of MR on the naïve ventricle. Additional work may be helpful to further elucidate these findings in a large animal model such as swine, where there are functional and physiological similarities to humans. ${ }^{6}$ Careful structural and hemodynamic analysis in patients with severe asymptomatic MR may also further illuminate the author's findings. Nonetheless, this early preclinical model provides substantial evidence to further support early surgical intervention in those patients with severe asymptomatic MR.

The findings presented by the authors merit commendation for illustrating a technically challenging yet reliable means for inducing and carefully analyzing the structural changes associated with severe MR. This model will continue to serve as a powerful tool to characterize the adverse consequences of severe MR. The careful structural and hemodynamic analysis provided by the Padala group will be influential in driving clinical decision-making and provide additional credo to intervene on asymptomatic MR before structural changes.

\section{References}

1. Nkomo VT, Gardin JM, Skelton TN, Gottdiener JS, Scott CG, Enriquez-Sarano M. Burden of valvular heart diseases: a population-based study. Lancet. 2006;368: 1005-11. 
2. Rosenhek R, Rader F, Klaar U, Gabriel H, Krejc M, Kalbeck D, et al. Outcome of watchful waiting in asymptomatic severe mitral regurgitation. Circulation. 2006; 113:2238-44.

3. Avierinos JF, Gersh BJ, Melton LJ. Natural history of asymptomatic mitral valve prolapse in the community. ACC Curr J Rev. 2003;12: $37-8$.

4. Nishimura RA, Otto CM, Bonow RO, Carabello BA, Erwin JP III, Fleisher LA, et al. 2017 AHA/ACC focused update of the 2014 AHA/ACC guideline for the management of patients with valvular heart disease. J Am Coll Cardiol. 2017; 70:252-89.

5. Corporan D, Onohara D, Amendi A, Saadeh M, Guton RA, Kumar S, et al. Hemodynamic and transcriptomic studies suggest early left ventricular dysfunction in a preclinical model of severe mitral regurgitation. J Thorac Cardiovasc Surg. 2021; 161:961-76.e22.

6. Lelovas PP, Kostomitsopoulos NG, Xanthos TT. A comparative anatomic and physiologic overview of the porcine heart. J Am Assoc Lab Anim Sci. 2014;53:432-8.
See Article page 961.

\section{Commentary: Can indications for asymptomatic mitral regurgitation derive from ratatouille or should we stew on it?}

Edward Buratto, MBBS, $\mathrm{PhD},{ }^{\mathrm{a}, \mathrm{b}, \mathrm{c}}$ and Igor E. Konstantinov, MD, PhD, FRACS ${ }^{\mathrm{a}, \mathrm{b}, \mathrm{c}, \mathrm{d}}$

Chronic mitral regurgitation (MR) is associated with progressive left ventricular (LV) volume loading, yet these patients may remain asymptomatic for many years without displaying any decrease in LV ejection fraction. ${ }^{1}$ It has been postulated that chronic severe MR may be associated with ventricular dysfunction that is not manifested as reduced ejection fraction. ${ }^{1,2}$ Furthermore, it has been observed that patients with preserved LV function who undergo mitral repair frequently have postoperative $\mathrm{LV}$ dysfunction. ${ }^{1}$ An interesting article by Corporan and colleagues ${ }^{3}$ describes an experimental rat model of MR, achieved by surgically perforating the anterior mitral leaflet. Over a period of 40 weeks, they observed that ventricular dilatation,

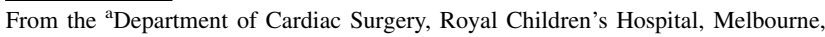
Australia; ${ }^{\mathrm{b}}$ Department of Paediatrics, University of Melbourne, Melbourne,

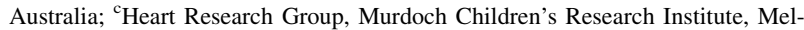
bourne, Australia; and ${ }^{\mathrm{d}}$ Melbourne Centre for Cardiovascular Genomics and Regenerative Medicine, Melbourne, Australia.

Disclosures: The authors reported no conflicts of interest.

The Journal policy requires editors and reviewers to disclose conflicts of interest and to decline handling or reviewing manuscripts for which they may have a conflict of interest. The editors and reviewers of this article have no conflicts of interest.

Received for publication Aug 31, 2020; revisions received Aug 31, 2020; accepted for publication Sept 1, 2020; available ahead of print Sept 4, 2020.

Address for reprints: Igor E. Konstantinov, MD, PhD, FRACS, Department of Cardiac Surgery, Royal Children's Hospital, Flemington Rd, Parkville, 3029, Australia (E-mail: igor.konstantinov@rch.org.au).

J Thorac Cardiovasc Surg 2021;161:978-9 0022-5223/ $\$ 36.00$

Crown Copyright (C) 2020 Published by Elsevier Inc. on behalf of The American Association for Thoracic Surgery

https://doi.org/10.1016/j.jtcvs.2020.09.006
Check for updates

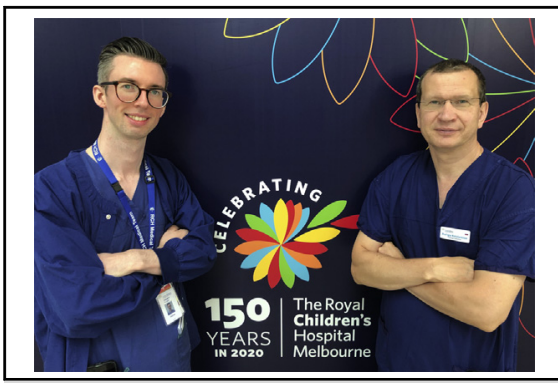

Edward Buratto, MBBS, PhD, and Igor E. Konstantinov, MD, PhD, FRACS

CENTRAL MESSAGE

In rat models of mitral regurgi-

tation, myocardial remodeling

may precede a fall in ejection

fraction.

impaired LV contractility, transcriptomic changes, myocardial remodeling, and oxidative stress pathways activation preceded a fall in LV ejection fraction. This appeared to be biological evidence to support the concept that ventricular dysfunction and adverse remodeling predates the fall in ejection fraction in patients with severe MR. Yet, this diverse mixture of transcriptomic changes, myocardial remodeling, and ventricular dilatation observed in rats is much like a thick ratatouille, the pieces of which are very difficult to separate and even harder to make sense of. Based on the findings in the rat model, it is difficult to make any clinical inferences for surgical management of asymptomatic patients with severe mitral insufficiency.

Given the concern of potential LV dysfunction despite preserved ejection fraction, the most recent American Heart Association guidelines recommend mitral repair in asymptomatic individuals with preserved ejection fraction if the probability of repair is $>95 \%$ and the risk of mortality 